\title{
Primary screening for human papillomavirus compared with cytology screening for cervical cancer in European settings: cost effectiveness analysis based on a Dutch microsimulation model
}

\author{
(c) $\frac{(1)(8)}{\mathrm{gy}}$ MPEN ACCESS
}

Inge M C M de Kok postdoctoral researcher ${ }^{1}$, Joost van Rosmalen postdoctoral researcher ${ }^{1}$, Joakim Dillner professor of infectious disease epidemiology ${ }^{2}$, Marc Arbyn head of unit ${ }^{3}$, Peter Sasieni professor of biostatistics and cancer epidemiology ${ }^{4}$, Thomas Iftner professor of biostatistics and cancer epidemiology ${ }^{5}$, Marjolein van Ballegooijen associate professor of epidemiology ${ }^{1}$

${ }^{1}$ Erasmus MC, University Medical Center, Department of Public Health, PO Box 2040, 3000 CA Rotterdam, Netherlands; ${ }^{2}$ Department of Laboratory Medicine, Lund University, Malmö University Hospital, Malmö, Sweden; ${ }^{3}$ Unit of Cancer Epidemiology, Scientific Institute of Public Health, Brussels, Belgium; ${ }^{4}$ Cancer Research UK Centre for Epidemiology, Mathematics and Statistics, Wolfson Institute of Preventive Medicine, Queen Mary University of London, London, UK; ${ }^{5}$ Institute for Medical Virology, University Hospital Tuebingen, Tuebingen, Germany

\begin{abstract}
Objectives To investigate, using a Dutch model, whether and under what variables framed for other European countries screening for human papillomavirus (HPV) is preferred over cytology screening for cervical cancer, and to calculate the preferred number of examinations over a woman's lifetime.
\end{abstract}

Design Cost effectiveness analysis based on a Dutch simulation model. Base case analyses investigated the cost effectiveness of more than 1500 different screening policies using the microsimulation model. Subsequently, the policies were compared for five different scenarios that represent different possible scenarios (risk of cervical cancer, previous screening, quality associated test characteristics, costs of testing, and prevalence of HPV).

Setting Various European countries.

Population Unvaccinated women born between 1939 and 1992.

Main outcome measures Optimal screening strategy in terms of incremental cost effectiveness ratios (costs per quality adjusted life years gained) compared with different cost effectiveness thresholds, for two levels of sensitivity and costs of the HPV test.

Results Primary HPV screening was the preferred primary test over the age of 30 in many considered scenarios. Primary cytology screening was preferred only in scenarios with low costs of cytology and in scenarios with a high prevalence of HPV in combination with high costs of HPV testing.

Conclusions Most European countries should consider switching from primary cytology to HPV screening for cervical cancer. HPV screening must, however, only be implemented in situations where screening is well controlled.

\section{Introduction}

Cytological screening has noticeably reduced the incidence of cervical cancer in countries with organised screening, ${ }^{1-3}$ but in Europe the disease still accounts for almost 57000 incident cases and 25000 deaths annually. ${ }^{4}$ Many European countries have introduced vaccination against the human papillomavirus (HPV), ${ }^{5}$ yet not all women are eligible. ${ }^{6}$ In such women cervical cancer screening remains the primary preventive strategy, and screening in unvaccinated women will continue for several decades. Because the current vaccines against HPV do not fully cover all the viral types that cause cancer, screening will be important for vaccinated women. How these women should be screened requires a specific analysis, which will be carried out separately and is therefore beyond the scope of this article.

In countries that have a history of cervical cancer screening (or consider setting up screening), it is being debated whether or not to replace cytology by HPV screening. Cytology has limited reproducibility, ${ }^{7}$ and meta-analyses and pooled analyses, both of cross sectional studies, have established that HPV tests have higher sensitivity than cytology for detecting high grade cervical intraepithelial neoplasia. ${ }^{8}$ Despite the clear higher sensitivity of HPV testing, there is hesitancy about changing to the test, and so far none of the screening guidelines or national programmes have actually switched to screening for HPV. Moreover, recent studies have shown that HPV screening or 
combined HPV and cytology screening has high negative predictive values for women who do not have high grade cervical intraepithelial neoplasia in the next screening round. ${ }^{10-13}$ As a result, joint European data suggested that screening intervals could be lengthened safely-for example, to six years among women with a negative HPV test result. ${ }^{10}$ Thus a lower required number of screening rounds would compensate, at least to some extent, for the lower specificity, which is the downside of HPV testing. The lower specificity is characterised by a higher positivity rate at every screening round and thus a larger associated burden of false positive test results and overtreatment of non-progressive cervical intraepithelial neoplasia.

How to weigh these pros and cons of HPV testing compared with cytology is not straightforward. Key variables are the quality of cytology screening and the prevalence of HPV infections relative to the level of risk for cervical cancer. This also holds for the costs of HPV testing relative to those of cytology, depending on quality assurance procedures, concentration of laboratory activities, and the costs of labour. Since these variables differ between countries, the unique characteristics of countries can lead to alternative preferred primary and triage screening tests.

We investigated the balance between benefits, burden, and costs of HPV screening compared with cytology screening for various scenarios based on combinations of variables observed in several European countries. We aimed to show under which realistic circumstances HPV screening is to be preferred to cytology screening from a cost effectiveness point of view. In addition, we calculated the optimal number of screening rounds over a woman's lifetime for each scenario, using different cost effectiveness thresholds.

\section{Methods}

Although we do not focus on exploring different triage strategies, we have included alternatives to ensure that we compared both primary cytology and primary HPV screening combined with optimal triage. We considered nine different strategies: one with primary cytology and cytology triage, four with primary HPV testing and cytology or a combination of cytology and HPV triage, and four with primary cytology and HPV or a combination of HPV and cytology triage (see graphic representation of screening strategies at http://hdl.handle.net/ $1765 / 31582$ ). The test strategies are based on guidelines or those proposed in the literature. ${ }^{9}$ 14-18

\section{The model}

To estimate differences in benefits, harms, and costs between HPV testing and cytology, we used the microsimulation screening analysis (MISCAN) model. ${ }^{19}$ This model simulates a large study population with individual life histories, in which women will, at a certain rate, acquire HPV infections, develop a preinvasive cervical lesion, and get cervical cancer. Some will die from the disease. Infections can also be cleared or produce cervical intraepithelial lesions that will regress. Women can acquire multiple infections during a lifetime, each with its own clinical course. The simulation results in an age specific and calendar time specific output of disease incidence and mortality. If the simulated population undergoes screening, some of the life histories will change. These changes constitute the effects of the intervention and are represented by the numbers of events and stages induced or prevented. The model produces the number of life years spent in each state as well as the number of certain events, such as screenings and cervical cancer diagnoses, in a woman's lifetime. We calculated a woman's quality adjusted life years (QALYs) as the weighted sum of the number of years spent in each of these states, using utility weights, which can range from 0 to 1 ; for some events, a fixed utility (which can be negative) is added to this weighted sum. The total effectiveness of screening (QALYs gained and life years gained) is determined as the difference in the number of life years gained/QALYs between the situation with screening and the situation without screening. We used a similar approach to determine the net costs of screening.

\section{Model specifications: demography, epidemiology, and clinical course}

The MISCAN cervix model was originally developed to simulate the Dutch situation. ${ }^{19}$ This model is validated on detailed data available from the Netherlands, ensuring a coherent model of the clinical course of cervical cancer. Given that data are insufficient to test the clinical course model for each country, it is reasonable to assume that transition probabilities and dwell times of preclinical stages are similar between countries, while varying the disease incidence to reflect different background risks. We varied other variables only if critical for the decision analyses, leaving those that will not significantly influence the outcome, as in the Dutch model. So, although we adjusted the model to the range in cervical cancer levels observed in Europe, we assumed that the age distributions of cervical intraepithelial neoplasia and cervical cancer were comparable in Europe and we estimated these age distributions based on the Dutch situation. This approach was also used for personal characteristics ${ }^{20}$ and hysterectomy rates. ${ }^{21}$ (See description of the data on which the model was calibrated at http://hdl.handle. net/1765/31582)

Disease is subdivided into seven sequential stages: high risk HPV infection (infection caused by an HPV type that can cause cancer and that can be detected by the HPV test), three preinvasive stages (cervical intraepithelial neoplasia grades I, II, and III), and three invasive stages (International Federation of Gynecology and Obstetrics (FIGO) stages IA, IB, and II or worse). Preinvasive and FIGO IA stages can be diagnosed by screening only, because no symptoms will develop, whereas stages IB and II or worse can also be clinically diagnosed. The disease is usually not progressive; in the model, most HPV infections will clear without ever resulting in neoplasia, and lesions in the preinvasive stages can regress spontaneously. If no mortality occurs from other causes, undetected preclinical invasive neoplasia will always progress to clinical cancer. In cervical intraepithelial neoplasia grades I and II a high risk HPV infection may or may not be present; if no high risk infection is present, the lesion will always regress. Cervical intraepithelial neoplasia grade III and invasive stages can only develop if a high risk HPV infection is present. (See durations of the different stages at http://hdl.handle.net/1765/31582.)

Given that our research question concerns unvaccinated women, we used a population model that simulated the life histories of eight million women born from 1939 to 1992 . Women born before 1939 are too old to attend screening after 2009, and women born after 1992 are eligible for HPV vaccination. Because of the expected lower risk of cancer in vaccinated women, a separate screening strategy will have to be determined for vaccinated cohorts in the future. We assumed that the simulated screening policies started in 2009 and continued until all simulated women had completed their screening programmes. Information on the screening pattern before 2009 was obtained from the Dutch national pathology database, assuming that the variation in screening activities in Europe will have a negligible influence on the effectiveness of the screening programme after 
2009. We derived the relative risks per birth cohort from an age-period-cohort analysis of cervical cancer mortality. ${ }^{22}$

\section{Assumptions for screening and treatment}

We assumed that $10 \%$ of the population never attends screening and has a three times higher background risk for cervical cancer than the $90 \%$ of potential attenders - that is, the high risk and low risk strata. ${ }^{23}$ From 2009 onwards we assumed the rate of potential attenders to be $80 \%$ for all primary screenings; in the model, follow-up screenings and referrals for colposcopy are always attended.

The HPV test uses the same type of cervical sample as does the cervical smear test. However, instead of placing cervical cells on a glass microscope slide, as in liquid based cytology, they are placed in a vial of liquid preservative. Testing for HPV is typically done using automated molecular amplification or hybridisation techniques. The test measures the presence of 13 high risk HPV types $(16,18,31,33,35,39,45,51,52,56,58$, 59 , and 68). Positive samples were those that attained or exceeded the threshold of $1.0 \mathrm{pg} / \mathrm{mL}$ of HPV DNA.

Table $1 \Downarrow$ presents the assumptions for screening. The sensitivity of the HPV test was estimated at $95 \%$ for a high risk HPV infection. ${ }^{24}$ Because uncertainty exists about the sensitivity of the HPV test ${ }^{8}$ we also assumed a sensitivity of $90 \%$. We assumed the sensitivity of the smear test (that is, the probability that the result is atypical squamous cells of undetermined significance or worse) for different disease stages to be $40 \%$ for cervical intraepithelial neoplasia grade I, 50\% for cervical intraepithelial neoplasia grade II, and $75 \%$ for cervical intraepithelial neoplasia III or worse. ${ }^{25}$ Because several triage strategies distinguish between a smear showing atypical squamous cells of undetermined significance or low grade squamous intraepithelial lesion and a smear with a result worse than low grade squamous intraepithelial lesion, we needed to specify the probability of a result worse than low grade squamous intraepithelial lesion for each stage. The sensitivity of testing for at least high grade squamous intraepithelial lesion (that is, the probability of low grade squamous intraepithelial lesion or worse) was assumed to be $4 \%$ for cervical intraepithelial neoplasia grade I, $19 \%$ for cervical intraepithelial neoplasia grade II, $47 \%$ for cervical intraepithelial neoplasia grade III, and $49 \%$ for cervical cancer. The specificity of the smear test was estimated to be $98.5 \%$ in the case of high quality, based on the false positive rate of smear test results in the Dutch screening programme. The specificity of the HPV test for HPV infections was assumed to be $100 \%$, because an eventual lack of specificity is modelled by including fast clearing infections.

Detection and the associated management of preinvasive lesions (including retreatment in some cases) were assumed to lead to a $100 \%$ cure rate. A woman can, however, develop a new HPV infection and neoplasia after treatment. For screen detected invasive cancers, the survival was modelled as a reduction in the risk of dying of cervical cancer compared with that of dying if the disease had been clinically diagnosed; this reduction for FIGO stages IA, IB, or II or worse was $80 \%, 60 \%$, or $20 \%$, respectively. As an example, this results in an average five year survival of about $97 \%$ for (screen detected) stage IA. ${ }^{22}$

\section{Assumptions for costs and utilities}

Table $2 \Downarrow$ presents the costs and utilities used in the analysis. Screening costs include the process used to invite women, the time and travel required to attend screening, the test, cytological evaluation or HPV analysis, and registration in the pathology database. We derived the costs of screening, diagnosis, and treatment procedures for detected preinvasive lesions, of primary treatment of invasive cervical cancer, and of treatment and palliative care for advanced cervical cancer from cost studies in the Netherlands. ${ }^{26}$ In the model, a small (psychological) loss in quality of life is assumed for attending a screen (including waiting for the result) and for being in triage (including attending follow-up screenings) after a positive primary test result. Larger losses in quality of life are assumed for receiving a diagnosis of cervical intraepithelial neoplasia or cancer and treatment and for having a terminal stage of cervical cancer. We based utilities on nationally and internationally published data. ${ }^{22} 27$

\section{Cost effectiveness analyses}

To ensure that the chosen age range and combinations of screening intervals would not affect the performance of HPV testing relative to the performance of cytology testing, we varied the ages at which screening takes place. We considered all screening policies with starting ages of $25,27,30$, or 32 that comprise at least three and at most 10 screenings and that have an interval of at least three years and at most 10 years; we did not simulate policies that include screenings over the age of 70 years. In total we simulated 1539 policy-strategy combinations (nine strategies multiplied by 171 policies).

In the results we account for the costs and effects of screening until all simulated women died. The total costs consist of those for invitations, primary and follow-up screenings, treatment of preinvasive and invasive cancer, and terminal care. We present the effects as the numbers of life years gained and QALYs gained by screening for cervical cancer. The cost effectiveness calculations were carried out from the adjusted societal perspective (not accounting for productivity losses due to illness and death). To convert future costs and health effects to the present, we discounted both costs and effects (life years and utility losses) at a rate of 3\% using 2009 as a reference year.

\section{Sensitivity analyses}

In the sensitivity analyses we compared all policy-strategy combinations simulated in the base case analysis for five different scenarios that represent contrasting real life situations (table $3 \Downarrow$ ). We based the scenarios on differences in characteristics observed between European countries that are relevant when HPV screening is compared with cytology screening: the risk of cervical cancer, previous screening, quality associated test characteristics, costs of the test, and prevalence of HPV. For one scenario (last column in table 3), with low costs for cytology, we also considered more intensive policies that comprised 11 to 20 screenings, including intervals of one and 10 years.

Cervical cancer risk-To cover the range of mortality levels in different European countries we assumed three background risks of cervical cancer related mortality; the risk of dying of cervical cancer in a situation without screening - namely, 5.0, 7.5, and 10 deaths per 100000 life years (table 1).

Previous screening - The existence of a screening programme before 2009 varied between European countries. Therefore we considered all simulated situations with and without previous screening (table 1). After taking into account past screening, the corresponding simulated mortality for invasive cervical cancer in 2009 was 2.0, 3.0, or 4.0 deaths per 100000 life years.

Quality associated test characteristics-We varied the assumptions for screening to account for observed differences between countries or for uncertainties (table 1). For scenarios with higher quality smear tests we assumed the same sensitivities as in the base case analysis. For scenarios with lower quality 
smear tests we assumed sensitivities of $32 \%$ for cervical intraepithelial neoplasia grade I, $40 \%$ for cervical intraepithelial neoplasia grade II, and $60 \%$ for cervical intraepithelial neoplasia grade III or worse. For these scenarios the sensitivity of testing for at least high grade squamous intraepithelial lesions was assumed to be $3 \%, 15 \%$, and $38 \%$, respectively. The specificity for higher quality tests was estimated to be $98.5 \%$, based on the rate of false positive smear test results in the Dutch screening programme. In case of low quality tests, the specificity was estimated to be $97 \%$.

Costs of the test-To consider differences in screening costs across Europe we also halved the total costs of cytology. Two possibilities were analysed for the laboratory costs of the HPV test: $€ 21.36$ ( $£ 17.86 ; \$ 28.00$ ) and $€ 33.23 .^{29}$

Prevalence of HPV - Given that in the model the increase in the risk of being infected with HPV is proportional to the increase in the risk of getting cervical cancer, the prevalence of HPV in the total population is $3 \%$ for a background risk of 5.0 deaths per 100000 life years, $4 \%$ for a risk of 7.5 deaths per 100000 life years, and 5\% for a risk of 10.0 deaths per 100000 life years. In some countries, however, the ratio between prevalence of HPV and risk of cervical cancer is higher. To represent these countries in scenarios with a higher prevalence of HPV we additionally doubled the number of triage tests after primary testing for HPV.

\section{Results}

For the six scenarios that reflect the differing situations for cervical cancer screening in Europe, the predicted costs and QALYs gained were determined for 1539 simulated screening strategies. To illustrate the influence of the different scenarios (base case and five scenarios) on the results of screening, the undiscounted results of three efficient screening strategies are presented (table $4 \Downarrow$ ): primary cytology with cytology triage and primary HPV screening with two times cytology triage and sensitivity of $90 \%$ or $95 \%$. In this example all women were screened from age 30 years and at intervals of five years until age 60 years. The number of triage screens increased with background risk and, more clearly, with a lower specificity of primary cytology or, in the case of primary HPV screening, with a higher prevalence of HPV (table 4). The numbers of cervical intraepithelial neoplasia grade II or III lesions, cases of cancer, and deaths from cervical cancer increased with the background risk for all screening strategies. A low sensitivity of the primary test resulted in a decrease in the number of detected cervical intraepithelial neoplasia grade II or III lesions and an increase in the number of cases of cancer and deaths (table 4).

To determine so called efficient strategies, those that were more costly and less effective than others were ruled out as non-efficient by simple dominance. Strategies that were more costly and less effective than a combination of other strategies were ruled out as non-efficient by extended dominance. The principle of extended dominance is applied in incremental cost effectiveness analysis to eliminate from consideration those strategies for which the costs and benefits are improved by a mixed strategy of two alternatives. ${ }^{30}$

The results show that primary HPV screening was preferred over primary cytology screening in most of the scenarios (table $5 \Downarrow$ ). In the two scenarios with a high prevalence of HPV, primary cytology screening was preferred only if higher costs for HPV screening were also assumed. In the scenario with low costs for cytology, primary cytology was preferred, notwithstanding the lower sensitivity and specificity that accompanied the lower costs. This result was independent of the background risk in the range considered (results not shown). The figure $\Downarrow$ shows the efficient frontier of the scenario of an average background risk and high prevalence of HPV for primary cytology screening and for primary HPV screening. It shows how primary cytology screening is dominated by primary HPV screening when the costs of HPV screening are low, and how primary HPV screening is dominated by primary cytology screening when the costs of HPV screening are high. In comparison, the efficient frontiers for the scenario of high risk with no past screening and a low sensitivity, specificity, and cost of cytology (see figure at http://hdl.handle.net/1765/31582) show how primary HPV screening is dominated by primary cytology screening. This figure also presents the number of examinations during a woman's lifetime. It shows that for the same number of QALYs gained five HPV tests could be carried out during a woman's lifetime, compared with eight cytological tests. In this scenario, however, eight times primary cytology is cheaper.

The intensity at which screening would still be cost effective mainly depended on the background risk of the scenario and on the cost effectiveness threshold applied (table $6 \Downarrow$ ). In scenarios with low background risk and with past screening (including base case scenario), three examinations during a lifetime were cost efficient at a threshold of $€ 20000$ per QALY gained and five at a threshold of $€ 50000$ per QALY gained. On the other hand, in the case of a high background risk and no past screening, 13 cytology examinations during a lifetime were cost efficient at a threshold of $€ 20000$ per QALY gained and 20 at the $€ 50000$ threshold. The age range increased accordingly from 30-46 years to $27-65$ years (table 6). The screening interval decreased from eight to three years.

An online calculation tool (available at http://hdl.handle.net/ $1765 / 31582$ ) can be used to calculate the cost effectiveness of the three efficient screening strategies from table 4, with different values for the specificity of cytology, the prevalence of HPV, the costs of screening and treatment, and the utilities lost for different stages of the screen process.

\section{Discussion}

Primary screening for HPV is preferred in many of the scenarios that would correspond to cervical cancer screening in various European countries. For countries with a high prevalence of HPV and high costs for the HPV test, however, primary cytology screening is preferred over primary HPV testing. Since population based primary HPV screening trials or programmes are not yet implemented in most European countries, reliable estimates for the prevalence of HPV are often not available and it is not clear whether the situation of high prevalence of HPV and high costs for the HPV test is common in Europe. Based on the results from trials of HPV screening and the reported incidence of cervical cancer, this situation seems the case in, for example, the United Kingdom and Italy. ${ }^{31-33}$ Regardless, the finding indicates that it is important to organise primary HPV screening in such a manner that the costs of the test are low. This can be achieved by concentrating the large numbers of HPV DNA tests in large laboratories to achieve economy of scale effects, such that the costs per test are lower if more test are analysed.

Primary cytological screening is also preferred in countries with low cytology screening costs, even when accounting for lower quality in terms of lower specificity and sensitivity of low cost cytology. Cytology with low costs, carried out by cytotechnicians, reflects low labour costs and is therefore relevant for some eastern European countries, such as Romania, 
Bulgaria, the Slovak Republic, and Latvia. ${ }^{34}$ It is recommended that countries with a high risk of cervical cancer or a high cost effectiveness threshold screen more intensively (that is, begin screening at a younger age, end at an older age, and have a shorter interval between the scheduled examinations) than countries with a low risk or a low cost effectiveness threshold, ranging from three to 20 examinations during a lifetime.

\section{Comparison with other studies}

Other published cost effectiveness analyses on HPV screening evaluated the combination of smear tests and HPV tests as primary screening and some studies evaluated HPV tests alone as the primary test. The publications provided costs and effect estimates, and incremental cost effectiveness ratios based on a comparison with screening programmes using smear tests, with intervals of $1,2,3$, and 5 years. The publications differ in many respects: they investigated different screening strategies in terms of the applied tests or test combinations, screening intervals, and target ages. The studies also differed in methodological approach (type of model, analytical time horizon, perspective of the analysis, and cost calculations). As a result the conclusions are heterogeneous: three analyses support primary HPV screening in a conventional cytology setting, ${ }^{29} 3536$ one supports it in a liquid based cytology setting but does not support it in a conventional cytology setting, ${ }^{37}$ one supports it in a conventional setting but does not support it in a liquid based cytology setting, ${ }^{38}$ and one does not support it in a conventional setting. ${ }^{28} \mathrm{We}$ quantified the importance of various levels and combinations of the sensitivity, specificity, and costs of each of the tests compared.

\section{Limitations of the study}

A limitation of our analysis is that we did not consider strategies that differ by age group. Some have suggested that screening for HPV DNA is not an acceptable screening test before age 30 years. ${ }^{39}$ It was also shown from a cost effectiveness point of view that primary cytology screening is preferred under the age of 30 and primary HPV testing over the age of $30 .^{40}$ The only cost effective policy in our results with screening under the age of 30 was primary cytology screening (table 6). In addition, HPV screening in young women at an increased cut-off point for a positive HPV test of $10 \mathrm{pg} / \mathrm{mL}$ HPV DNA could be an option. $^{41}$

We adapted the model to particular country situations by varying epidemiological (background risk and past screening) and screening characteristics (test sensitivity, specificity, and costs). The scenario of average background risk and high prevalence of HPV, for example, is based on the situation in Italy and the United Kingdom; the scenario of average background risk and low test sensitivity and specificity of cytology is based on the situation in Germany; the scenario of low risk, low specificity of cytology is based on the situation in Finland; the scenario of high risk, high prevalence of HPV the situation in Denmark; and the scenario of high risk, no past screening, and low sensitivity, specificity, and costs of cytology the situation in Romania. Some of the variables that were not varied in the sensitivity analyses were still based on Dutch data. For instance, in addition to the incidence of cervical cancer (which was varied), the age pattern of the incidence (which was not varied) may differ between countries. ${ }^{42}$ In some countries the peak age specific incidence in setting of no screening was estimated to occur at an older age than the 45 years estimated for the Netherlands. ${ }^{43}$ Also, personal characteristics were not varied. None of these differences will, however, influence the preferred type of primary screen test in a specific country, which was why we did not include them in the list of adjusted variables.

Information on the prevalence of HPV compared with the risk of cervical cancer in different countries is lacking. We used the percentage of HPV positive women in European randomised controlled trials of cervical cancer screening, with HPV testing as the primary screen ${ }^{32}$ compared with the incidence of cervical cancer in these countries. The prevalence of HPV measured in the randomised controlled trial setting may not be exactly representative of the real situation in a specific country. But even if the assumptions we have made in the sensitivity analyses are not correct, it does show the probable effect of the HPV prevalence:cervical cancer incidence ratio.

We assumed that $10 \%$ of the population never attends screening and has a three times higher background risk for cervical cancer than the $90 \%$ potential attenders (the high risk stratum and the low risk stratum), based on international data when mass screening for cervical cancer started. ${ }^{23}$ If this healthy screener selection is not applicable (anymore), we could have underestimated the effect of screening and thus also the cost effectiveness. Nevertheless, the preferred type of primary screen test would again not change. Furthermore, we assumed that follow-up screenings and referrals for colposcopy are always attended. This assumption could have led to an overestimation of the effect of primary HPV screening compared with cytology screening, because more women are referred for follow-up tests in cases of primary HPV screening. We found that if an attendance rate of $90 \%$ at triage was assumed in the base case situation, primary HPV testing is still the most cost effective option. ${ }^{44}$

The use of QALYs as an outcome measure in cost effectiveness modelling is recommended by the Panel of Cost-Effectiveness in Health and Medicine, ${ }^{45}$ but depends on the reliability of quantification of quality of life aspects of screening and cervical cancer. Given that HPV screening has a higher positive rate than cytology, our conclusion that primary HPV screening is preferred to cytology screening is sensitive to the loss of utility associated with a triage episode (until referral to screening or colposcopy) after a positive HPV test result. We found, for example, in the base case situation that if the utility loss associated with follow-up screenings was the equivalent of seven days of life instead of two days of life per year spent in triage, primary cytological screening with HPV triage would be more cost effective than primary HPV testing. ${ }^{44}$

Men were not included in our model. Men do influence the prevalence of HPV in the female population, owing to sexual interaction. Since HPV screening has a higher sensitivity, more HPV infection can in theory be removed from the population. So the chance of becoming infected with HPV could be lower in the case of HPV screening. Nevertheless, this effect will be small, and including men would probably not result in other outcomes.

\section{Policy recommendations}

We showed that primary HPV screening is to be preferred in most European settings. However, implementing HPV screening in situations where screening is not well controlled carries risks that may be unacceptable. Frequent screening at a young age decreases the programme's specificity given that every screening round adds to false positive test results (that is, the detection of non-progressive HPV infections or cervical intraepithelial neoplasia lesions), and screening at a young age detects many transient infections and abnormalities. Overtreatment of young women that may occur with false positive test results (both with 
HPV testing and cytology) can have adverse health and pregnancy outcomes. Uneven distribution of HPV screening over the population, with frequent screening at young age, may affect the balance between benefits on the one hand and harms and costs on the other. In addition, HPV screening should be organised in such a way that the procedures are carried out in large centres to monitor the quality of the screening and to benefit from economies of scale. This is especially the case for HPV testing, which can be automated to a large extent, and where economies of scale will make a considerable difference to costs.

\section{Conclusion}

We carried out an extensive simulation study, using a Dutch model, to investigate under which realistic European conditions HPV testing is to be preferred to cytology screening as a primary test for the detection of cervical cancer. Primary HPV screening was preferred in most of the scenarios considered. Primary cytology screening was only preferred in scenarios with low costs of cytology and in scenarios with high prevalence of HPV in combination with high costs of HPV testing. Therefore most European countries should seriously consider switching from primary cytology to HPV screening. Such screening must, however, only be implemented in situations where screening is already well controlled.

Contributors: IMCMdK and JVR did the analyses. TI is the principal investigator of the total $\mathrm{EU}$ project. MvB is the principal investigator of this specific research project. All authors contributed to writing the manuscript. IMCMdK and MvB are the guarantors.

Funding: This study was supported by a grant from the European Union, European Union Biomed 5 contract HPV-based cervical cancer screening (QLG4-CT2000-01238). It was partly supported by a grant from the Dutch National Institute for Public Health and the Environment (RIVM, grant No 019/09 pDG/NvdV/EMG). PS was supported by a Cancer Research UK programme grant (C8162/A10406). The study sponsor had no role in the design of the study; the collection, analysis, or interpretation of the data; the writing of the manuscript; or the decision to submit the manuscript for publication.

Competing interests: All authors have completed the ICMJE uniform disclosure form at www.icmje.org/coi_disclosure.pdf and declare: IMCMdK, MvB, and JvR were supported by the European Union and the Dutch National Institute for Public Health and the Environment, MA was supported by the European Union and the Belgian Foundation against Cancer, and JD was supported by the European Union; IMCMdK and MvB have received a grant from GlaxoSmithKline that might have an interest in the submitted work in the previous three years; MA has received a grant from the University of Gent that might have an interest in the submitted work in the previous three years; TI has received money for consultancy from Siemens Healthcare, grants from Roche, Hologic, and Gen-Probe, payment for lectures including service on speakers bureaus from with Hologic, Gen-Probe, Roche Diagnostics, Sanofi Pasteur MSD, Siemens Healthcare Diagnostics, GlaxoSmithKline, Qiagen, and Greiner BioOne, and patents from Greiner BioOne, that might have an interest in the submitted work in the previous three years; PS has received a grant from the Cancer Research UK programme, money for consultancy from Gen-Probe, and travel/accommodations/meeting expenses from GlaxoSmithKline that might have an interest in the submitted work in the previous three years; JD has received a grant from Merck/Sanofi Pasteur MSD that might have an interest in the submitted work in the previous three years; and no other relationships or activities that could appear to have influenced the submitted work.

Ethical approval: Not required.
Data sharing: Model inputs, technical details, and more extensive or intermediate results are available from the corresponding author at i.dekok@erasmusmc.nl. Extra material supplied by the author is also available at http://hdl.handle.net/1765/31582: graphic representation of screening strategies; efficient frontier of scenario of high risk with no past screening and low sensitivity, specificity, and cost of cytology for primary cytology and primary HPV screening; description of MISCAN-cervix model; and calculation tool.

1 Bray F, Loos AH, McCarron P, Weiderpass E, Arbyn M, Moller H, et al. Trends in cervica squamous cell carcinoma incidence in 13 European countries: changing risk and the squamous cell carcinoma incidence in 13 European countries: changing risk
effects of screening. Cancer Epidemiol Biomarkers Prev 2005;14:677-86.

2 Karim-Kos HE, de Vries E, Soerjomataram I, Lemmens V, Siesling S, Coebergh JW. Recent trends of cancer in Europe: a combined approach of incidence, survival and mortality for 17 cancer sites since the 1990s. Eur J Cancer 2008:44:1345-89.

3 Arbyn M, Raifu AO, Weiderpass E, Bray F, Anttila A. Trends of cervical cancer mortality in the member states of the European Union. Eur J Cancer 2009;45:2640-8.

4 Arbyn M, Raifu AO, Autier P, Ferlay J. Burden of cervical cancer in Europe: estimates for 2004. Ann Oncol 2007; 18:1708-15.

5 Levy-Bruhl D, Bousquet V, King LA, O'Flanagan D, Bacci S, Lopalco PL, et al. The current state of introduction of HPV vaccination into national immunisation schedules in Europe: results of the VENICE 2008 survey. Eur J Cancer 2009:45:2709-13.

6 Hildesheim A, Herrero R, Wacholder S, Rodriguez AC, Solomon D, Bratti MC, et al. Effect of human papillomavirus 16/18 L1 viruslike particle vaccine among young women with preexisting infection: a randomized trial. JAMA 2007;298:743-53.

7 Stoler MH, Schiffman M. Interobserver reproducibility of cervical cytologic and histologic interpretations: realistic estimates from the ASCUS-LSIL Triage Study. JAMA 2001;285:1500-5.

8 Arbyn M, Sasieni P, Meijer CJ, Clavel C, Koliopoulos G, Dillner J. Clinical applications of HPV testing: a summary of meta-analyses. Vaccine 2006;24(suppl 3):S3/78-89.

9 Cuzick J, Clavel C, Petry KU, Meijer CJ, Hoyer H, Ratnam S, et al. Overview of the European and North American studies on HPV testing in primary cervical cancer screening. Int J Cancer 2006;119:1095-101.

10 Dillner J, Rebolj M, Birembaut P, Petry KU, Szarewski A, Munk C, et al. Long term predictive values of cytology and human papillomavirus testing in cervical cancer screening: joint European cohort study. BMJ 2008;337:a1754.

11 Hoyer $\mathrm{H}$, Scheungraber C, Kuehne-Heid R, Teller K, Greinke C, Leistritz S, et al. Cumulative 5-year diagnoses of CIN2, CIN3 or cervical cancer after concurrent high-risk HPV and cytology testing in a primary screening setting. Int $J$ Cancer 2005;116:136-43.

12 Petry KU, Menton S, Menton M, van Loenen-Frosch F, de Carvalho Gomes H, Holz B, et al. Inclusion of HPV testing in routine cervical cancer screening for women above 29 years in Germany: results for 8466 patients. Br J Cancer 2003;88:1570-7.

13 Sherman ME, Lorincz AT, Scott DR, Wacholder S, Castle PE, Glass AG, et al. Baseline cytology, human papillomavirus testing, and risk for cervical neoplasia: a 10-year cohort analysis. J Natl Cancer Inst 2003;95:46-52.

14 Coupe VM, de Melker HE, Snijders PJ, Meijer CJ, Berkhof J. How to screen for cervical cancer after HPV16/18 vaccination in the Netherlands. Vaccine 2009;27:5111-9.

15 Naucler P, Ryd W, Tornberg S, Strand A, Wadell G, Elfgren K, et al. Efficacy of HPV DNA testing with cytology triage and/or repeat HPV DNA testing in primary cervical cancer screening. J Natl Cancer Inst 2009;101:88-99.

16 Rebolj M, van Ballegooijen M, Berkers LM, Habbema D. Monitoring a national cancer prevention program: successful changes in cervical cancer screening in the Netherlands. Int J Cancer 2007:120:806-12.

17 Dutch Society for Pathology. Guideline draft 2.0. Quality assurance of cytopathological investigation of the cervix. [In Dutch.] NVVP, 2006.

18 Rebolj M, Bais AG, van Ballegooijen M, Boer R, Meerding WJ, Helmerhorst TJ, et al. Human papillomavirus triage of women with persistent borderline or mildly dyskaryotic smears: comparison of costs and side effects of three alternative strategies. Int J Cancer 2007:121:1529-35

19 Habbema JD, van Oortmarssen GJ, Lubbe JT, van der Maas PJ. The MISCAN simulation program for the evaluation of screening for disease. Comput Methods Programs Biomed 1985;20:79-93.

20 CBS (Netherlands Central Bureau of Statistics). Death by cause of death, age and sex 1950-1992. CBS, 1994.

21 SIG (Information Centre for Health Care). Hospital diagnosis statistics 1963-1985. SIG, 1985.

22 Van Ballegooijen M. Effects and costs of cervical cancer screening. [Thesis, 1998.

23 Van Oortmarssen GJ, Habbema JD. Epidemiological evidence for age-dependent regression of pre-invasive cervical cancer. Br J Cancer 1991;64:559-65.

24 Bulk S, Bulkmans NW, Berkhof J, Rozendaal L, Boeke AJ, Verheijen RH, et al. Risk of high-grade cervical intra-epithelial neoplasia based on cytology and high-risk HPV testing at baseline and at 6-months. Int $J$ Cancer 2007;121:361-7.

25 Berkhof J, de Bruijne MC, Zielinski GD, Meijer CJ. Natural history and screening model for high-risk human papillomavirus infection, neoplasia and cervical cancer in the Netherlands. Int J Cancer 2005;115:268-75.

26 Van Ballegooijen M, Rebolj M, Essink-Bot ML, Meerding WJ, Berkers LM, Habbema JDF. De effecten en kosten van het bevolkingsonderzoek naar baarmoederhalskanker in Nederland na de herstructurering. Erasmus MC, afdeling Maatschappelijke Gezondheidszorg, 2006

27 Goldie SJ, Kohli M, Grima D, Weinstein MC, Wright TC, Bosch FX, et al. Projected clinical benefits and cost-effectiveness of a human papillomavirus $16 / 18$ vaccine. J Natl Cancer Inst 2004;96:604-15.

28 Mandelblatt JS, Lawrence WF, Womack SM, Jacobson D, Yi B, Hwang YT, et al. Benefits and costs of using HPV testing to screen for cervical cancer. JAMA 2002;287:2372-81.

29 Berkhof J, Coupe VM, Bogaards JA, van Kemenade FJ, Helmerhorst TJ, Snijders PJ, et al. The health and economic effects of HPV DNA screening in the Netherlands. Int $J$ Cancer 2010;127:2147-58.

30 Cantor SB. Cost-effectiveness analysis, extended dominance, and ethics: a quantitative assessment. Med Decis Making 1994;14:259-65.

31 Ronco G, van Ballegooijen M, Becker N, Chil A, Fender M, Giubilato P, et al. Process performance of cervical screening programmes in Europe. Eur J Cancer 2009;45:2659-70. 


\section{What is already known on this topic}

Cervical cancer screening using human papillomavirus (HPV) tests has higher sensitivity but lower specificity than cytology for detecting clinically relevant lesions

The conclusions of other published cost effectiveness analyses on HPV screening are heterogeneous

\section{What this study adds}

Primary HPV screening is preferred in many of the scenarios that would correspond to the cervical cancer screening situation of various European countries

In countries with high prevalence of HPV and high costs for the HPV test, primary cytology screening is preferred over primary HPV testing, indicating that it is important to organise primary HPV screening so that the costs of the test are low

32 Lynge E, Rebolj M. Primary HPV screening for cervical cancer prevention: results from European trials. Nat Rev Clin Oncol 2009;6:699-706.

33 Karim-Kos HE, de Vries E, Soerjomataram I, Lemmens V, Siesling S, Coebergh JW. Recent trends of cancer in Europe: a combined approach of incidence, survival and mortality for 17 cancer sites since the 1990s. Eur J Cancer 2008:44:1345-89.

34 OECD. Unit labour costs-annual indicators. 2010. www.oecd.org.

35 Kim JJ, Wright TC, Goldie SJ. Cost-effectiveness of human papillomavirus DNA testing in the United Kingdom, the Netherlands, France, and Italy. J Natl Cancer Inst 2005;97:888-95.

36 Mittendorf T, Petry KU, Iftner T, Greiner W, von der Schulenburg JM. Economic evaluation of human papillomavirus screening in Germany. Eur J Health Econ 2003:4:209-15.

37 Sherlaw-Johnson C, Philips Z. An evaluation of liquid-based cytology and human papillomavirus testing within the UK cervical cancer screening programme. Br J Cancer 2004;91:84-91.

38 Goldie SJ, Kim JJ, Wright TC. Cost-effectiveness of human papillomavirus DNA testing for cervical cancer screening in women aged 30 years or more. Obstet Gynecol 2004;103:619-31.

39 Wright TC Jr, Schiffman M, Solomon D, Cox JT, Garcia F, Goldie S, et al. Interim guidance for the use of human papillomavirus DNA testing as an adjunct to cervical cytology for screening. Obstet Gynecol 2004;103:304-9.

40 Goldhaber-Fiebert JD, Stout NK, Salomon JA, Kuntz KM, Goldie SJ. Cost-effectiveness of cervical cancer screening with human papillomavirus DNA testing and HPV-16,18 vaccination. J Nat/ Cancer Inst 2008:100:308-20.

41 Zhao FH, Lin MJ, Chen F, Hu SY, Zhang R, Belinson JL, et al. Performance of high-risk human papillomavirus DNA testing as a primary screen for cervical cancer: a pooled analysis of individual patient data from 17 population-based studies from China. Lancet Oncol 2010;11:1160-71

42 Van Ballegooijen M, Boer R, van Oortmarssen GJ, Koopmanschap MA, Lubbe JTHN, Habbema JDF. Cervical cancer screening: age ranges and intervals. An updated cost-effecitiviteitsanalyse. [In Dutch.] Instituut Maatschappelijke Gezondeheidszorg, Erasmus University Rotterdam, 1993.

43 Gustafsson L, Ponten J, Bergstrom R, Adami HO. International incidence rates of invasive cervical cancer before cytological screening. Int J Cancer 1997;71:159-65.

44 Van Rosmalen J, de Kok IM, van Ballegooijen M. Cost-effectiveness of cervical cancer screening: cytology versus human papillomavirus DNA testing. BJOG 2012; published online $18 \mathrm{Jan}$.

45 Siegel JE, Weinstein MC, Russell LB, Gold MR. Recommendations for reporting cost-effectiveness analyses. Panel on Cost-Effectiveness in Health and Medicine. JAMA 1996;276:1339-41.

\section{Accepted: 14 November 2011}

\section{Cite this as: BMJ 2012:344:e670}

This is an open-access article distributed under the terms of the Creative Commons Attribution Non-commercial License, which permits use, distribution, and reproduction in any medium, provided the original work is properly cited, the use is non commercial and is otherwise in compliance with the license. See: http://creativecommons.org/licenses/bync/2.0/ and http://creativecommons.org/licenses/by-nc/2.0/legalcode. 


\section{Tables}

Table 1| Model inputs: variables that were varied between scenarios, and values considered. Values are percentages unless stated otherwise

\begin{tabular}{lc} 
Variables & \multicolumn{1}{c}{ Alternative values } \\
Background risk of cervical cancer mortality & $5.0 / 7.5 / 10$ per 100000 \\
\hline Past screening (cytology) & Yes/No \\
\hline Sensitivity (probability of at least ASCUS) of cytology for CIN grade ${ }^{25}$ : & $40 / 32$ \\
\hline CIN grade I & $50 / 40$ \\
\hline CIN grade II & $75 / 60$ \\
\hline CIN grade III or worse & \\
\hline Probability of at least HSIL for CIN grades: & $4 / 3$ \\
\hline CIN grade I & $19 / 15$ \\
\hline CIN grade II & $47 / 38$ \\
\hline CIN grade III or worse & $97 / 98.5$ \\
\hline Specificity of cytology (for CIN grade I or worse) & $90 / 95$ \\
\hline Sensitivity of HPV test (for high risk HPV infection) $)^{24}$ & Low/High \\
\hline Prevalence of HPV in CIN grade I or less* & $21 / 33$ \\
\hline Laboratory costs $(€)$ HPV screening & $26 / 52$ \\
\hline Total cost ( $€$ ) cytology & $20000 / 30000 / 50000$ per QALY gained \\
\hline Threshold value (€) for cost effectiveness &
\end{tabular}

$€ 1.00(£ 0.84 ; \$ 1.31)$.

See table 2 for rounded up values for laboratory costs of screening and total cost of cytology.

ASCUS=atypical squamous cells of undetermined significance; $C I N=$ cervical intraepithelial neoplasia; $H S I L=h i g h$ grade squamous intraepithelial lesion; QALY=quality adjusted life year.

*Depends on background risk of cervical cancer mortality. On top of increased HPV prevalence associated with a higher background risk, to account for the possibility of a country with a high prevalence of HPV, the number of women with a positive HPV test result and without cytological abnormalities was multiplied by a factor of 2 . If the background risk was 5 deaths per 100000 life years, the mean prevalence of HPV in the total population would be $6 \%$ in the case of high prevalence and $3 \%$ in the case of low prevalence; if the background risk was 7.5 deaths per 100000 life years, the mean prevalence in the total population would be $8 \%$ or $4 \%$; and if the background risk was 10 deaths per 100000 life years, the mean prevalence in the total population would be $10 \%$ or $5 \%$. 
Table 2| Model inputs: costs and level and duration of loss of utilities for events and health states that are induced or prevented by screening (costs are in 2008 prices)

\begin{tabular}{|c|c|c|c|}
\hline \multirow[b]{2}{*}{ Model inputs } & \multirow[b]{2}{*}{ Costs $(€)$} & \multicolumn{2}{|c|}{ Utilities lost } \\
\hline & & Level & Duration \\
\hline Invitation & 4.65 & 0 & - \\
\hline Primary cytology screening: & & 0.006 & 2 weeks \\
\hline Laboratory costs of test & 21.36 & & \\
\hline Organisation & 11.02 & & \\
\hline General practitioner costs & 11.54 & & \\
\hline Time and travel & 5.90 & & \\
\hline Programme costs & 2.04 & & \\
\hline Total & $25.94 / 51.88 \dagger$ & & \\
\hline Repeat cytology test: & & 0.006 & Time since last test* \\
\hline General practitioner costs & 21.79 & & \\
\hline Laboratory costs & 26.04 & & \\
\hline Time and travel & 5.90 & & \\
\hline Primary HPV screening: & & 0.006 & 2 weeks \\
\hline Laboratory costs of test & $33.23 / 21.36$ & & \\
\hline Organisation & 11.02 & & \\
\hline General practitioner costs & 11.54 & & \\
\hline Time and travel & 5.90 & & \\
\hline Programme costs & 2.04 & & \\
\hline Repeat HPV test: & & 0.006 & Time since last test \\
\hline General practitioner costs & 21.79 & & \\
\hline Laboratory costs & 33.23 & & \\
\hline Time and travel & 5.90 & & \\
\hline \multicolumn{4}{|l|}{ Diagnoses and treatment } \\
\hline \multicolumn{4}{|l|}{ Preinvasive $\mathrm{CIN}:$} \\
\hline False positive & 279 & 0.005 & 0.5 year \\
\hline Stage I & 869 & 0.03 & 0.5 year \\
\hline Stage II & 1287 & 0.07 & 1 year \\
\hline Stage III & 1507 & 0.07 & 1 year \\
\hline \multicolumn{4}{|l|}{ Invasive cancer (FIGO stages): } \\
\hline IA & 4935 & 0.062 & 5 years \\
\hline IB & 11703 & 0.062 & 5 years \\
\hline II or worse (screen detected) & 11535 & 0.28 & 5 years \\
\hline II or worse (clinically detected) & 10773 & 0.28 & 5 years \\
\hline Terminal care & 26209 & 0.712 & 1 month \\
\hline
\end{tabular}

$€ 1.00(£ 0.84 ; \$ 1.31)$.

$\mathrm{CIN}=$ cervical intraepithelial neoplasia; FIGO=International Federation of Gynecology and Obstetrics.

*Two weeks, if a woman is invited for a repeat test immediately after a positive primary test result; six months; or 12 months.

†To consider differences in screening costs across Europe, total costs were also halved. 
Table 3| Base case scenario and five scenarios of realistic combinations of variables. The scenarios were based on differences in characteristics observed between European countries

\begin{tabular}{|c|c|c|c|c|c|c|c|}
\hline \multirow[b]{2}{*}{ Parameters } & \multirow[b]{2}{*}{ Possibilities } & \multirow[b]{2}{*}{$\begin{array}{c}\text { Base case } \\
\text { scenario (low } \\
\text { risk) }\end{array}$} & \multicolumn{5}{|c|}{ Scenarios in sensitivity analyses } \\
\hline & & & $\begin{array}{c}\text { Average risk, } \\
\text { high HPV } \\
\text { prevalence }\end{array}$ & $\begin{array}{l}\text { Average risk, low } \\
\text { sensitivity and } \\
\text { specificity of } \\
\text { cytology }\end{array}$ & $\begin{array}{l}\text { Low risk, low } \\
\text { specificity of } \\
\text { cytology }\end{array}$ & $\begin{array}{l}\text { High risk, high } \\
\text { HPV prevalence }\end{array}$ & $\begin{array}{l}\text { High risk; no past } \\
\text { screening; low } \\
\text { sensitivity, } \\
\text { specificity, and costs } \\
\text { of cytology }\end{array}$ \\
\hline Past screening & Yes/No & Yes & Yes & Yes & Yes & Yes & No \\
\hline Risk without screening & $\begin{array}{c}\text { 5.0/7.5/10.0 per } \\
100000\end{array}$ & 5.0 & 7.5 & 7.5 & 5.0 & 10.0 & 10.0 \\
\hline $\begin{array}{l}\text { Prevalence (\%) of } \\
\text { HPV in total } \\
\text { population }\end{array}$ & Low/High* & Low (3) & High (8) & Low (4) & Low (3) & High (10) & Low (5) \\
\hline \multicolumn{8}{|l|}{ Cytology: } \\
\hline Sensitivity (\%) & $60 / 75 \dagger$ & 75 & 75 & 60 & 75 & 75 & 60 \\
\hline Specificity (\%) & $97 / 98.5$ & 98.5 & 98.5 & 97 & 97 & 98.5 & 97 \\
\hline Total costs $(€) \ddagger$ & $26 / 52$ & 52 & 52 & 52 & 52 & 52 & 26 \\
\hline \multicolumn{8}{|l|}{ HPV test: } \\
\hline Laboratory costs $(€) \S$ & $21 / 33$ & $21 / 33$ & $21 / 33$ & $21 / 33$ & $21 / 33$ & $21 / 33$ & $21 / 33$ \\
\hline Sensitivity (\%)§ & $90 / 95$ & $90 / 95$ & $90 / 95$ & $90 / 95$ & $90 / 95$ & $90 / 95$ & $90 / 95$ \\
\hline
\end{tabular}

Risk refers to background risk of cervical cancer mortality throughout.

$€ 1.00(£ 0.84 ; \$ 1.31)$.

*Prevalence is $97 \%$ for countries with background risk of 5.0 per 100000 life years, $96 \%$ for background risk of 7.5 per 100000 life years, and $95 \%$ for background risk of 10.0 per 100,000 life years. To account for possible high prevalence in a country the number of women with a false positive test result was multiplied by a factor of 2.

†Sensitivity for all CIN (cervical intraepithelial neoplasia) stages (see table 1) was varied with same relative change (60\%:75\%); sensitivity for CIN III or worse was given as example.

łIncluding organisation costs.

§Both possibilities analysed because of uncertainty about these parameters. 
Table 4| Example of undiscounted results of primary cytology screening with cytology triage (see scenario 5 in web extra figure on bmj.com) and two type of primary human papillomavirus (HPV) screening and cytology triage with varying sensitivity of HPV screening (scenario 3 in web extra). Women are screened seven times during a lifetime, starting at age 30 , and at intervals of five years

\begin{tabular}{|c|c|c|c|c|c|}
\hline Scenarios & $\begin{array}{c}\text { Mean No of primary } \\
\text { screens per simulated } \\
\text { woman* }\end{array}$ & $\begin{array}{l}\text { Triage screens (\% of } \\
\text { first primary smears) }\end{array}$ & $\begin{array}{c}\text { CIN II or III lesions } \\
\text { (\% of first primary } \\
\text { smears) }\end{array}$ & $\begin{array}{l}\text { Cancer cases (per } \\
100000 \text { life years) }\end{array}$ & $\begin{array}{c}\text { Deaths from cervical } \\
\text { cancer (per } 100000 \\
\text { life years) }\end{array}$ \\
\hline \multicolumn{6}{|c|}{ Primary cytology screening with cytology triage } \\
\hline Base case (low risk): & 2.13 & 3.3 & 0.3 & 5.7 & 2.6 \\
\hline Average risk, high HPV prevalence & 2.13 & 3.6 & 0.4 & 8.5 & 3.9 \\
\hline $\begin{array}{l}\text { Average risk, low sensitivity and specificity } \\
\text { of cytology }\end{array}$ & 2.13 & 6.2 & 0.4 & 9.6 & 4.4 \\
\hline Low risk, low specificity of cytology & 2.13 & 6.1 & 0.3 & 5.7 & 2.6 \\
\hline High risk, high HPV prevalence & 2.13 & 3.9 & 0.6 & 11.2 & 5.2 \\
\hline $\begin{array}{l}\text { High risk, no past screening, and low } \\
\text { sensitivity, specificity, and cost of cytology }\end{array}$ & 2.13 & 6.4 & 0.6 & 15.9 & 7.2 \\
\hline \multicolumn{6}{|c|}{ Primary HPV screening with two times cytology triage, sensitivity of HPV screening $90 \%$} \\
\hline Base case (low risk): & 2.13 & 4.8 & 0.3 & 5.3 & 2.5 \\
\hline Average risk, high HPV prevalence & 2.13 & 13.3 & 0.4 & 7.9 & 3.7 \\
\hline $\begin{array}{l}\text { Average risk, low sensitivity and specificity } \\
\text { of cytology }\end{array}$ & 2.13 & 7.3 & 0.4 & 8.6 & 3.9 \\
\hline Low risk, low specificity of cytology & 2.13 & 4.8 & 0.3 & 5.3 & 2.5 \\
\hline High risk, high HPV prevalence & 2.14 & 17.6 & 0.6 & 10.5 & 4.9 \\
\hline $\begin{array}{l}\text { High risk, no past screening, and low } \\
\text { sensitivity, specificity, and cost of cytology }\end{array}$ & 2.13 & 9.9 & 0.7 & 14.2 & 6.4 \\
\hline \multicolumn{6}{|c|}{ Primary HPV screening with two times cytology triage, sensitivity of HPV screening $95 \%$} \\
\hline Base case (low risk): & 2.13 & 5.1 & 0.3 & 5.2 & 2.4 \\
\hline Average risk, high HPV prevalence & 2.14 & 14.0 & 0.4 & 7.8 & 3.6 \\
\hline $\begin{array}{l}\text { Average risk, low sensitivity and specificity } \\
\text { of cytology }\end{array}$ & 2.13 & 7.7 & 0.4 & 8.5 & 3.9 \\
\hline Low risk, low specificity of cytology & 2.13 & 5.1 & 0.3 & 5.2 & 2.4 \\
\hline High risk, high HPV prevalence & 2.14 & 18.5 & 0.6 & 10.3 & 4.8 \\
\hline $\begin{array}{l}\text { High risk, no past screening, and low } \\
\text { sensitivity, specificity, and cost of cytology }\end{array}$ & 2.13 & 10.3 & 0.7 & 13.9 & 6.3 \\
\hline
\end{tabular}


Table 5| Preferred primary test for different levels of sensitivity of human papillomavirus (HPV) screening (90\% v 95\%), and laboratory costs of HPV test (€21 v €33)

\begin{tabular}{|c|c|c|c|c|}
\hline \multirow[b]{2}{*}{ Scenarios } & \multicolumn{2}{|c|}{ Laboratory costs HPV test $€ 21$} & \multicolumn{2}{|c|}{ Laboratory costs HPV test $€ 33$} \\
\hline & $90 \%$ sensitive & $95 \%$ sensitive & $90 \%$ sensitive & $95 \%$ sensitive \\
\hline Base case (low risk): & HPV & HPV & HPV & HPV \\
\hline Average risk, high HPV prevalence & HPV & HPV & Cytology & Cytology \\
\hline Average risk, low sensitivity and specificity of cytology & HPV & HPV & HPV & HPV \\
\hline Low risk, low specificity of cytology & HPV & HPV & HPV & HPV \\
\hline High risk, high HPV prevalence & HPV & HPV & Cytology & Cytology \\
\hline $\begin{array}{l}\text { High risk, no past screening, and low sensitivity, specificity, and } \\
\text { cost of cytology }\end{array}$ & Cytology & Cytology & Cytology & Cytology \\
\hline
\end{tabular}

Results were consistent for incremental cost effectiveness thresholds between $€ 20000$ and $€ 50000$ per QALY gained. $€ 1.00(£ 0.84 ; \$ 1.31)$. 
Table $6 \mid$ Number of screening rounds and age ranges of preferred strategy (see table 5) per threshold of cost effectiveness ${ }^{*}$ where sensitivity of human papillomavirus (HPV) screening is $90 \%$ or $95 \%$, and laboratory costs of HPV test are $€ 21$ or $€ 33$

\begin{tabular}{|c|c|c|c|c|c|c|c|c|c|c|c|c|}
\hline \multirow[b]{3}{*}{ Scenarios } & \multicolumn{6}{|c|}{ Laboratory costs HPV test $€ 21$} & \multicolumn{6}{|c|}{ Laboratory costs HPV test $€ 33$} \\
\hline & \multicolumn{3}{|c|}{$90 \%$ sensitivity } & \multicolumn{3}{|c|}{$95 \%$ sensitivity } & \multicolumn{3}{|c|}{$90 \%$ sensitivity } & \multicolumn{3}{|c|}{ 95\% sensitivivity } \\
\hline & 20000 & 30000 & 50000 & 20000 & 30000 & 50000 & 20000 & 30000 & 50000 & 20000 & 30000 & 50000 \\
\hline $\begin{array}{l}\text { Base case (low } \\
\text { risk) }\end{array}$ & $3(30-46)$ & $4(30-54)$ & $5(30-58)$ & $3(30-46)$ & $4(30-54)$ & $5(30-62)$ & $3(30-46)$ & $3(30-46)$ & $5(30-54)$ & $3(30-46)$ & $3(30-46)$ & $4(30-54)$ \\
\hline $\begin{array}{l}\text { Average risk, high } \\
\text { HPV prevalence }\end{array}$ & $4(30-54)$ & $5(30-60)$ & $8(25-67)$ & $4(32-56)$ & $5(30-58)$ & $8(27-69)$ & $5(30-50) \dagger$ & $6(30-55) \dagger$ & $8(30-65) \dagger$ & $5(30-50) \dagger$ & $6(30-55) \dagger$ & $8(30-65) \dagger$ \\
\hline $\begin{array}{l}\text { Average risk, low } \\
\text { sensitivity and } \\
\text { specificity of } \\
\text { cytology }\end{array}$ & $4(32-53)$ & $5(30-58)$ & $8(30-65)$ & $4(32-56)$ & $5(30-58)$ & $7(30-66)$ & $3(32-46)$ & $5(30-58)$ & $6(30-65)$ & $4(30-54)$ & $5(30-58)$ & $7(30-66)$ \\
\hline $\begin{array}{l}\text { Low risk, low } \\
\text { specificity of } \\
\text { cytology }\end{array}$ & $3(30-46)$ & $4(30-54)$ & $5(30-58)$ & $3(30-46)$ & $4(30-54)$ & $5(30-65)$ & $3(30-46)$ & $4(30-46)$ & $5(30-58)$ & $3(30-46)$ & $4(30-46)$ & $5(30-54)$ \\
\hline $\begin{array}{l}\text { High risk, high } \\
\text { HPV prevalence }\end{array}$ & $5(32-53)$ & $7(30-58)$ & $10(30-65)$ & $5(32-56)$ & $7(30-58)$ & $9(30-66)$ & $6(30-55) \dagger$ & $7(30-60) \dagger$ & $\begin{array}{c}10(30-66) \\
\dagger\end{array}$ & $6(30-55) \dagger$ & $7(30-60) \dagger$ & $\begin{array}{c}10(30-66) \\
\dagger\end{array}$ \\
\hline $\begin{array}{l}\text { High risk, no past } \\
\text { screening, low } \\
\text { sensitivity, } \\
\text { specificity, and } \\
\text { cost of cytology }\end{array}$ & $\begin{array}{c}13 \\
(30-66) \dagger\end{array}$ & $\begin{array}{c}17 \\
(30-62) \dagger\end{array}$ & $\begin{array}{c}20 \\
(27-65) \dagger\end{array}$ & $\begin{array}{c}13 \\
(30-66) \dagger\end{array}$ & $\begin{array}{c}17 \\
(30-62) \dagger\end{array}$ & $\begin{array}{c}20 \\
(27-65) \dagger\end{array}$ & $\begin{array}{c}13 \\
(30-66) \dagger\end{array}$ & $\begin{array}{c}17 \\
(30-62) \dagger\end{array}$ & $\begin{array}{c}20 \\
(27-65) \dagger\end{array}$ & $\begin{array}{c}13 \\
(30-66) \dagger\end{array}$ & $\begin{array}{c}17 \\
(30-62) \dagger\end{array}$ & $\begin{array}{c}20 \\
(27-65) \dagger\end{array}$ \\
\hline $\begin{array}{l}€ 1.00(£ 0.84 ; \$ 1.3 \\
{ }^{*} \text { Costs }(€) \text { per QAL } \\
\text { †Primary cytology }\end{array}$ & $\begin{array}{l}\text { 1). } \\
\text { Y gained. } \\
\text { based prog }\end{array}$ & mme. & & & & & & & & & & \\
\hline
\end{tabular}




\section{Figure}

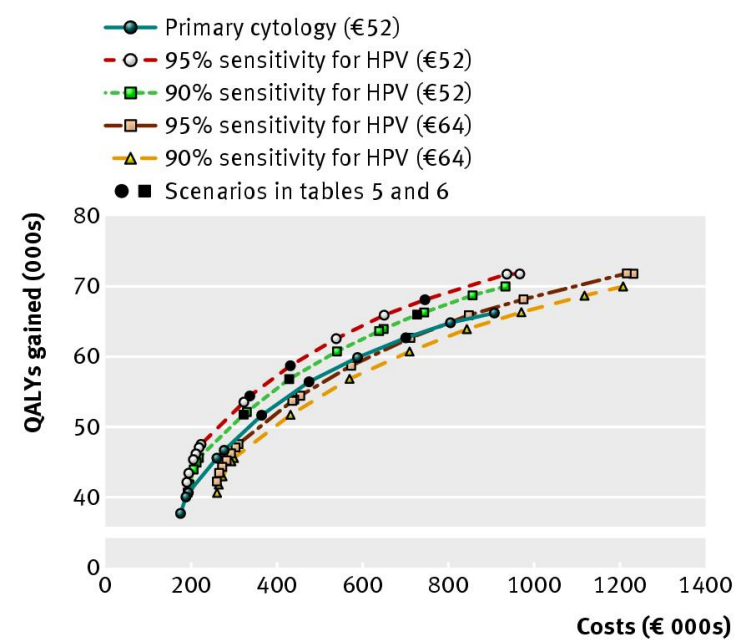

Representation of simulated efficient frontiers of scenario of an average background risk and high prevalence of HPV when assuming only primary cytology screening or only primary HPV screening for different assumptions about HPV testing (90\% or $95 \%$ sensitivity and $€ 52$ or $€ 64$ total costs). Each mark represents an efficient programme with different screening ages. Costs (€000s) and effects (000s) of quality adjusted life years (QALYs) gained, $3 \%$ discount rate for costs and effects 